\title{
E-learning e innovación social. Introducción
}

\author{
Jordi Planella \\ Israel Rodríguez
}

La idea de organizar una jornada sobre la perspectiva social del e-learning surgió de la necesidad de proporcionar un marco de debate, entre académicos y profesionales interesados en las perspectivas más sociales, que permitiera discutir sobre las perspectivas y concepciones disponibles acerca del e-learning en los entornos de educación superior. Creíamos firmemente en la necesidad de tratar, desde un punto de vista académico, temas como la inclusión y la responsabilidad social, el desarrollo y la solidaridad. Sobre ellos pivotó la sesión internacional de trabajo.

A partir de las ponencias de estas interesantes jornadas sobre la perspectiva social del e-learning, que ofrecen un espacio para la reflexión, se ha confeccionado el monográfico, que a su vez constituirá el primer número de la revista electrónica RUSC (Revista de Universidad y Sociedad del Conocimiento) donde irán apareciendo, además de los monográficos (procedentes especialmente de los talleres o workshops organizados por la Cátedra), artículos y reseñas sobre los ámbitos de conocimiento de la Cátedra y estudios de casos.

Con este debate quisimos proporcionar las herramientas conceptuales, teóricas y prácticas que nos ayudasen a comprender los principales efectos y consecuencias sociales y culturales derivados de la creciente implementación, diseño y uso de plataformas de enseñanza y aprendizaje basadas en lo que hoy conocemos como $e^{-}$ learning. Ciertamente, dichos efectos son el eje de nuestros ámbitos de interés y estudio. Por este motivo consideramos importante detenernos a pensar y reflexionar de un modo crítico alrededor de estos temas.
La discusión en torno a los efectos y consecuencias de los cambios tecnológicos, sociales y culturales que afectan a nuestras sociedades y, en concreto, al ámbito educativo, es sin duda uno de los temas más apasionantes y acuciantes de la transformación social, institucional, organizativa y cultural que estamos viviendo con el paso hacia la sociedad de la información. Muchas de ellas, sin embargo, están planteadas desde posturas extremas, irreconciliables, o que se reparten por igual filias y fobias. Sin embargo, la tecnología no es ni buena, ni mala, ni neutra. Se articula con un conjunto de prácticas sociales, a las que reforma, transforma y condiciona. De igual modo, los actores y colectivos sociales dan sentido y se apropian, transforman y manipulan una tecnología que, a su vez, se resiste a ciertos usos. Es en esta interacción, en este espacio medio, donde se da un conjunto de posibilidades y una casuística distintas.

No obstante, demasiadas veces soslayamos este tipo de debates y prescindimos de ellos y de miradas sobre el cambio tecnológico que viven nuestras sociedades. A nuestro juicio hace falta explorar más esas posibilidades sin caer en meras dimensiones propagandísticas. Hace falta un debate más sereno, centrado en casos prácticos, ejemplos y experiencias que nos permitan ver ese tejido sin costuras con el que articulamos tecnología y sociedad, y en este caso concreto en campos educativos. Ésta fue nuestra intención en esta sesión de trabajo, aunque se tratara de un ejercicio de reflexión introductoria. Afortunadamente, el ejercicio reunía condiciones inmejorables en sus ponentes y en su orientación interdisciplinar y plural, y creó un espacio amplio y abierto para el debate y la reflexión intelectual. 
En ese sentido, puesto que en este momento lo tecnológico forma parte de la misma carne de lo social, creímos importante reflexionar sobre lo que sin duda es uno de los retos e hitos más estimulantes que afrontará nuestra sociedad: el fenómeno educativo en una sociedad del conocimiento y la información.

\section{E-LEARNING E INNOVACIÓN SOCIAL: LA NECESIDAD DE UN DEBATE INTERDISCIPLINAR}

Desde hace ya casi una década, la explosión de Internet y las llamadas tecnologías de la información y la comunicación han generado profundas transformaciones sociales y culturales. Nuestra dinámica antropológica se ve modificada - por el alcance y la magnitud del cambio- por la incursión de las TIC. Como en su tiempo las redes eléctricas, el televisor o la máquina de vapor, las TIC están modificando radicalmente el contexto y la misma forma en la que tienen lugar nuestras relaciones e intercambios sociales. Nuestras sociedades se esculpen sobre entramados tecnológicos que reúnen características distintas a otras formas de relación precedentes. Las TIC transmiten y almacenan información, conectan espacios y tiempos distintos, y tienen un alcance prácticamente planetario. Las simulaciones interactivas, las bases de datos, los hipervínculos, el texto escrito y los recursos multimedia pasan a ser el tablero de juego en el que se dan muchas de nuestras relaciones. Nos movemos en espacios fluidos, en arquitecturas enredadas, por autopistas veloces de intercambio de información; nos conectamos y expandimos por lanzaderas virtuales que proyectan nuestros relatos, nuestros conocimientos y poderes, e incluso nuestros cuerpos a latitudes poco previsibles hace unos años. Y esto, claro está, modifica buena parte de nuestros hábitos sociales, y modifica buena parte de nuestros paisajes culturales. Modifica, en resumen, la sociedad - en sus formas más específicas- que cada día levantamos entre todos.

Tales cambios han desembocado en un sinfín de debates y discusiones sobre sus efectos en campos tan dispares como la economía, la política, la cultura o la propia sociedad. La educación no es ajena a tales cambios ni tampoco a la necesidad de un debate sobre sus transformaciones y su papel en las sociedades actuales.

En este sentido, asistimos a una dinámica creciente de implementación, diseño y uso de plataformas de enseñanza y aprendizaje basadas en lo que hoy conocemos con el epígrafe de e-learning. Sin duda, esto tiene importantes consecuencias sociales y culturales, y constituye la piedra angular sobre la que giran muchas de nuestras conversaciones y muchas de nuestras inquietudes, como ciudadanos y como profesionales. Sobre todo cuando nos dirigimos a sus efectos y transformaciones en el ámbito universitario. Las universidades se están transformando profundamente: su organización, su estructura, su papel y su encaje en un nuevo entorno social y cultural, de corte global, constituyen preocupaciones sin duda relevantes hoy en día.

Este debate se vuelve más acuciante cuando dirigimos nuestra mirada hacia muchas de las desigualdades y problemas sociales que emergen, o se acrecientan, en esta era digital. La exclusión social y los retos para la convivencia toman también nuevos derroteros en las sociedades y estructuras surgidas de Internet. En este punto, la educación tiene de nuevo un importante papel que desempeñar. El e-learning constituye sin duda una plataforma de esperanza en este sentido. Por ello consideramos importante orientar la discusión del workshop hacia el papel que la enseñanza superior actual, a través de las plataformas de e-learning, puede tener en la era digital, especialmente en su contribución hacia una sociedad global responsable, justa e inclusiva cultural y socialmente.

Habitamos redes que transportan y dan sentido a nuestras ideas, emociones, vínculos y relaciones, mediante latitudes y temporalidades hasta el momento inexplotables por otros medios y formas de relación. Esto transforma el mapa sobre el que crecer, las funciones y las formas que toman nuestros equipamientos colectivos, instituciones y demás. La morfología 
de una sociedad entera se transforma: es la denominada sociedad red. La metáfora de la red es ubicua y explica buena parte de estas modificaciones y la naturaleza que están tomando muchas de nuestras formas de convivencia, instituciones e incluso colectivos o grupos electivos de los que formamos parte. De entre todo ello emerge el e-learning como potencialidad y posibilidad, así como preocupación de fondo, inundando el espacio del pensamiento de preguntas e interrogantes: ¿qué efectos tiene esto para la universidad?; en un mundo de flujos, de abstracciones, de temporalidades fluidas, de ciudadanías globales, de formas políticas desterritorializadas, de mercados globales, de culturas entremezcladas e interrelacionadas, ¿qué papel le queda a la cultura, al saber, a la educación?; ¿en qué puede contribuir el e-learning?; ¿qué hacer ante las nuevas y viejas desigualdades? Acrecentadas las diferencias por los mercados globalizados y las economías de nuevo cuño, aparecen también problemas sociales a los que hay que dar respuesta comprendiendo y aportando profesionales dotados para intervenir. La universidad siempre ha sido un medio privilegiado de relación, comprensión, reflexión e intervención en el entorno problemático, en riesgo de exclusión, etc. ¿Qué papel puede desempeñar hoy en día?, ¿qué papel puede tener este palacio de los vientos en una sociedad convulsionada y atrapada en problemas de viejo y nuevo cuño?, ¿a qué conflictos debemos hacer frente en nuestras sociedades y qué papel le queda a la universidad?

Tales preocupaciones son las que han inundado dicho espacio de debate y las que han dado lugar a una mirada que puede dividirse en distintos planos: el relativo al papel del e-learning en nuestras sociedades, el relativo a la transformación de lo educativo mediante la virtualización de determinadas relaciones e instituciones sociales y el relativo al propio impacto del e-learning como caballo de batalla de una nueva sociedad informacional. Dichos planos, creemos, dan buena cuenta de las principales inquietudes a las que debemos enfrentarnos y debemos comprender, en el presente y en el futuro inmediato.

Tenemos la convicción de que en épocas de cambio como la que vivimos hace falta un debate sereno, centrado en casos prácticos, en ejemplos y experiencias que nos permitan reflexionar sobre estos cambios desde el ámbito educativo. Esto es precisamente lo que hemos pretendido hacer discutiendo y analizando la perspectiva social del e-learning.

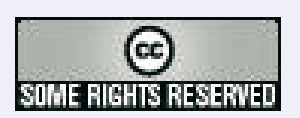

Los textos publicados en esta revista están sujetos -si no se indica lo contrario- a una licencia de Reconocimiento 3.0 España de Creative Commons. Puede copiarlos, distribuirlos, comunicarlos públicamente y hacer obras derivadas siempre que reconozca los créditos de las obras (autoría, nombre de la revista, institución editora) de la manera especificada por los autores o por la revista. La licencia completa se puede consultar en http://creativecommons.org/licenses/by/3.0/es/deed.es. 